\title{
Comparative analysis of whole flower transcriptomes in the Zingiberales
}

\author{
Ana Maria R Almeida ${ }^{\text {Corresp., }}{ }^{1}$, Alma Piñeyro-Nelson ${ }^{2}$, Roxana B Yockteng ${ }^{3}$, Chelsea D Specht ${ }^{4,5}$ \\ 1 Department of Biological Sciences, California State University, Hayward, Hayward, CA, United States \\ 2 Department of Food and Animal Production, Autonomous Metropolitan University, Xochimilco, Mexico City, DF, Mexico \\ 3 Centro de Investigaciones Tibaitatá, Corporación Colombiana de Investigación Agropecuaria (CORPOICA), Tibaitatá, Colombia \\ 4 Department of Plant and Microbial Biology \& Integrative Biology, University of California at Berkeley, Berkeley, CA, US \\ 5 College of Agriculture and Life Sciences, Cornell University, Ithaca, NY, United States \\ Corresponding Author: Ana Maria R Almeida \\ Email address: ana.almeida@csueastbay.edu
}

The advancement of next generation sequencing technologies (NGS) has revolutionized our ability to generate large quantities of data at a genomic scale. Despite great challenges, these new sequencing technologies have empowered scientists to explore various relevant biological questions on non-model organisms, even in the absence of a complete sequenced reference genome. Here, we analyzed whole flower transcriptome libraries from exemplar species across the monocot order Zingiberales, using a comparative approach in order to gain insight into the evolution of the molecular mechanisms underlying flower development in the group. We identified 4,153 coding genes shared by all floral transcriptomes analyzed, and 1,748 genes that are only retrieved in the Zingiberales. We also identified 666 genes that are unique to the ginger lineage, and 2,001 that are only found in the banana group, while in the outgroup species Dichorisandra thyrsiflora J.C. Mikan (Commelinaceae) we retrieved 2,686 unique genes. It is possible that some of these genes underlie lineage-specific molecular mechanisms of floral diversification. We further discuss the nature of these lineage-specific datasets, emphasizing conserved and unique molecular processes with special emphasis in the Zingiberales. We also briefly discuss the strengths and shortcomings of de novo assembly for the study of developmental processes across divergent taxa from a particular order. Although this comparison is based exclusively on coding genes, with particular emphasis in transcription factors, we believe that the careful study of other regulatory mechanisms, such as non-coding RNAs, might reveal new levels of complexity, which were not explored in this work. 
2

Comparative analysis of whole flower transcriptomes in the Zingiberales

Almeida, AMR. .,\$,1; Piñeyro-Nelson, A. ${ }^{*}, 2$; Yockteng, R. ${ }^{3}$; Specht, CD. ${ }^{4}$

* These authors contributed equally to this work

${ }^{1}$ Department of Biological Sciences, California State University East Bay, 25800 Carlos Bee Boulevard, Hayward, CA, US. 94542.

${ }^{2}$ Department of Food and Animal Production, Autonomous Metropolitan University, Xochimilco, Mexico City, Mexico, 04960.

${ }^{3}$ Corporación Colombiana de Investigación Agropecuaria (CORPOICA), Centro de Investigaciones Tibaitatá, Colombia and Institut de Systématique, Évolution, Biodiversité, UMR7205-CNRS Muséum National d'Histoire Naturelle, Paris, France.

${ }^{4}$ Department of Plant and Microbial Biology, Department of Integrative Biology, University of California at Berkeley, Berkeley, CA, and College of Agriculture and Life Sciences. Cornell University, Ithaca, NY, US.

\$ corresponding author: ana.almeida@csueastbay.edu

\section{Abstract}

The advancement of next generation sequencing technologies (NGS) has revolutionized our ability to generate large quantities of data at a genomic scale. Despite great challenges, these new sequencing technologies have empowered scientists to explore various relevant biological questions on non-model organisms, even in the absence of a complete sequenced reference genome. Here, we analyzed whole flower transcriptome libraries from exemplar species across the monocot order Zingiberales, using a comparative approach in order to gain insight into the evolution of the molecular mechanisms underlying flower development in the group. We identified 4,153 coding genes shared by all floral transcriptomes analyzed, and 1,748 genes that are only retrieved in the Zingiberales. We also identified 666 genes that are unique to the ginger lineage, and 2,001 that are only found in the banana group, while in the outgroup species Dichorisandra thyrsiflora J.C. Mikan (Commelinaceae) we retrieved 2,686 unique genes. It is possible that some of these genes underlie lineage-specific molecular mechanisms of floral 
32 diversification. We further discuss the nature of these lineage-specific datasets, emphasizing

33 conserved and unique molecular processes with special emphasis in the Zingiberales. We also

34 briefly discuss the strengths and shortcomings of de novo assembly for the study of

35 developmental processes across divergent taxa from a particular order. Although this comparison

36 is based exclusively on coding genes, with particular emphasis in transcription factors, we

37 believe that the careful study of other regulatory mechanisms, such as non-coding RNAs, might

38 reveal new levels of complexity, which were not explored in this work.

39

40

41

42

43

44

45

46

47

48

49

50

51

52

53

54

55

56

57

58

59

60

61

62

\section{Introduction}

Next-generation sequencing technologies have been instrumental in allowing for the rapid generation of large quantities of transcriptomic data, previously unavailable for the majority of non-model organisms. In parallel to refinements of the sequencing technologies, several bioinformatics pipelines have been put forward allowing for the de novo assembly of transcriptomes from organisms for which there is not a fully sequenced and annotated genome ('reference genome' e.g., Wit et al. 2012; Chiara et al. 2013; Singhal 2013; Unamba et al. 2015). Although long predicted as a revolutionary tool (Wang et al. 2009), RNA-Seq approaches enabling the comparative quantification of gene expression during organismal development have recently gained wide use across a diversity of organisms representing unique developmental and physiological processes. These advances have enabled the identification of candidate genes involved in a variety of processes ranging from flower color [e.g., pigment biosynthesis in Camellia reticulata (Yao et al. 2016); color polymorphism in Silene littorea Brot. (CasimiroSouriguer et al. 2016)] to characterization of biosynthetic pathways [e.g., glucosinolate and phytochelatin pathways in Sinapsis alba L. (Zhang at al. 2016); flavonoid and stilbenoids pathways in Gnetum parvifolium (Warb.) W.C.Cheng (Deng et al. 2016)]. NGS approaches have also been used to study plant architecture (González-Plaza et al. 2016) as well as specific aspects of reproductive development (Hollender et al. 2014).

Chanderbali and colleagues $(2009 ; 2010)$ pioneered the use of next-generation sequencing technologies to study the comparative evolution of floral development across angiosperms. Their choice of plant species included representatives of main angiosperm lineages (i.e., water lily, avocado, California poppy, and Arabidopsis), as well as a non-angiosperm seed plant (cycad), which allowed the authors to obtain insights into the molecular mechanisms 
63 underlying the evolution and diversification of the flower (Chanderbali et al. 2010). While there

64 was deep conservation in the genetic programs specifying floral organ identities, further confirmed by the careful study of 18 angiosperm genomes (Davila-Velderrain et al. 2013), it was also possible to identify distinct transcriptional programs characterizing more recently derived plant lineages (Chanderbali et al. 2010). Thus, one can hypothesize that these distinct transcriptional programs are likely involved with mechanisms of diversification in floral shape, especially in closely related species.

In order to gain insight into the genetic basis of floral morphological variation, we present a comparative transcriptomic analysis of several species within the angiosperm order Zingiberales. The Zingiberales is a lineage of tropical and subtropical monocots comprising 8 families. The order includes economically important species such as culinary ginger (Zingiber officinale Roscoe), turmeric (Curcuma longa L.), and banana (Musa acuminata Colla), as well as popular ornamentals, such as Canna indica L., bird-of-paradise (Strelitzia reginae Banks), spiral gingers (Costus spp.), and heliconias (Heliconia spp.). A recent phylogenetic analysis (Sass et al. 2016) supports the placement of Musaceae as sister to all other lineages followed by a monophyletic clade comprising Heliconiaceae, Strelitziaceae and Lowiaceae. Together, these 4 families are referred to as the "banana lineages" and form a basal paraphyly with respect to the derived monophyletic ginger clade (Cannaceae, Marantaceae, Costaceae, and Zingiberaceae $=$ "ginger clade") (Figure 1a). Flower morphology in the Zingiberales varies dramatically, and one of the main floral transitions in the order is related to the androecial whorl. Throughout the evolution of the Zingiberales, the number of fertile stamens is drastically reduced from 5-6 fertile stamens in the banana lineages to 1 or $1 / 2$ fertile stamen in the ginger clade. This reduction in fertile stamen number is inversely correlated to an increase in petaloidy, in which the infertile androecial members laminarize (flatten) and develop into petal-like organs (Almeida et al. 2015a) (Figure 1b).

Several gene and gene networks have been hypothesized as underlying the molecular mechanisms of Zingiberales floral developmental evolution (Bartlett \& Specht 2010; Yockteng et al. 2013a; Almeida et al. 2014; Almeida et al 2015b). However intriguing, these studies are

91 limited to candidate-gene or candidate-process approaches. In this study, we present an analysis

92 of whole flower transcriptomes of several species spanning the Zingiberales order, as well as of a 93 closely related Commelinaceae species. We focus our comparative analysis on coding regions, 
94 with particular attention to transcription factors. This broad approach aims at avoiding the pitfalls

95 of targeted candidate-based methodologies, and can potentially illuminate lineage-specific

96 mechanisms of floral development linked to evolution and diversification in form and function.

97 We also highlight the advancements and challenges of comparative transcriptome-based

98 approaches for the study of developmental evolution.

99

\section{Methods}

101 Plant Material and RNA extractions

102

Whole developing flowers of Costus spicatus, Zingiber officinale, Calathea zebrina

103 (Sims) Lindl., Canna sp., Orchidantha fimbriata Holttum, Musa basjoo Siebold \& Zucc., and

104 Dichorisandra thyrsiflora were collected at the UC Berkeley Botanical Garden, Oxford Track

105 Greenhouse, and UC Davis Greenhouse (Table 1). Whole young floral buds were collected and

106 immediately flash frozen in liquid nitrogen. Flower and/or inflorescence size and morphology

107 vary widely within the Zingiberales, and uniform developmental stages have not yet been

108 established for the different lineages. In all cases, young inflorescences were dissected as much

109 as possible and the youngest discernable floral buds were collected.

$110 \quad$ Frozen floral buds were stored in $-80^{\circ} \mathrm{C}$ for up to two days before RNA extraction. Total

111 RNA was extracted from floral material using Plant RNA Extraction Reagent (Invitrogen,

112 Carlsbad, CA, USA), according to Yockteng et al. (2013b). RNA was stored at $-80{ }^{\circ} \mathrm{C}$ until

113 further use.

114

115 Library Preparation and sequencing

116 cDNA libraries for sequencing on the Illumina platform were prepared using the TruSeq

117 RNA sample prep kit v2. cDNA libraries were prepared with 2,0 $\mu \mathrm{g}$ of RNA extracted from flash

118 frozen floral buds. Costus spicatus whole flower library was sequenced using the Illumina

119 HiSeq2000 at IIGB HT Sequencing Facility at the University of California, Riverside. All other

120 samples were multiplexed 1:1 using barcode set A. Multiplexed libraries were sequenced using

121 Illumina HiSeq2000 High Output at Vincent J. Coates Genomics Sequencing Lab at University

122 of California at Berkeley. All libraries were sequenced as 100bp pair-end reads.

123

124 Data cleanup and transcriptome assembly 
125 Data clean-up was performed using a custom Perl script involving the following steps: (i)

126 removal of identical forward and reverse reads; (ii) removal of duplicated reads in order to

127 decrease the computational burden of subsequent de novo assembly; (iii) trimming of adapters,

128 low complexity, and low quality (Q-score $<20)$ unique sequences using a combination of

129 cutadapt v1.9.1 (Martin 2011), Blat v348 (Kent 2002), and Trimmomatic v0.35 (Bolger et al.

130 2014); (iv) screening of reads for contaminants against the human and Escherichia coli genomes

131 using Bowtie v1.1.1 (Langmead et al. 2009). Clean-up quality was assed comparing FastQC

132 v0.11.2 (http://www.bioinformatics.babraham.ac.uk/projects/fastqc/) reports of cleaned and raw

133 reads.

134 Transcriptomes were assembled de novo using Trinity v2.1.0 (Grabherr et al. 2011) with

135 a variety of parameters. The best assembly results (based on the quality assessments presented

136 below) used default parameters for all other species despite discrepancies in the overall estimated

137 transcriptome coverage and number of reads. Contigs larger than $300 \mathrm{bp}$ were retained and

138 further annotated.

139 Quality assessment of de novo assemblies was performed using DETONATE v1.10 (Li \&

140 Fillmore et al. 2014). In particular, RSEM-EVAL was used as a reference-free evaluation

141 method. True transcript length was estimated through comparison to several predicted

142 transcriptomes from the sequenced genomes of Musa acuminata (d'Hont et al. 2012), the palms

143 Phoenix dactylifera (Al-Mssallem et al. 2013) and Elaeis guineensis (Singh et al. 2013), and the

144 core eudicot Arabidopsis thaliana (The Arabidopsis Genome Initiative 2000). The number of

145 coding sequences (CDS) in these species ranged from 28,889 in Phoenix dactylifera to 35,386 in

146 Arabidopsis thaliana and 36,549 in Musa acuminata, to in 44,360 in Elaeis guineensis.

147 Further quality assessment was performed on the basis of number and length of contigs as

148 well as N50 (Table 02).

149

150 Transcriptome annotation and comparison

151 Statistically supported contigs were annotated with the help of TransDecoder v4.1.0

152 (https://transdecoder.github.io/). First, coding regions were identified using TransDecoder long

153 ORFs prediction. Predicted long ORFs were subjected to a Blastp search (Gish \& States 1993)

154 using Blast+ v2.7.1 against the Uniprot database (The UniProt Consortium 2015), as well as a

155 HMMER3 v3.1b2 (Eddy 1998) search against the Pfam database (Finn et al. 2016). The results 
156 from the Blastp and HMMER3 searches were used by TransDecoder to filter likely coding 157 regions from the predicted long ORFs list. For each species, TransDecoder-predicted coding 158 regions were further filtered, using a Blastp search to the Uniprot database and the following 159 parameters: $>=70 \%$ identity; E-value $=<1.0 \mathrm{e}^{-5}$; alignment length $>=100 \mathrm{bp}$; and coverage of at 160 least $40 \%$. These stringent lists were used as inputs for whole flower transcriptome comparisons, 161 in order to avoid the inclusion in the analyses of chimeras and/or truncated transcripts.

162 Orthology between transcriptome predicted long-ORFs and CDS of sequenced genomes 163 of Musa acuminata (d'Hont et al. 2012), Phoenix dactylifera (Al-Mssallem et al. 2013), Elaeis

164 guineensis (Singh et al. 2013), and Arabidopsis thaliana (The Arabidopsis Genome Initiative 165 2000) were established using OrthoFinder v2.2.3. Functional annotation of orthogroups were 166 based on gene counterparts of the sequenced genomes of Arabidopsis thaliana (TAIR10) and 167 Elaeis guineensis. Filtered contigs were also annotated based on nucleotide Blastn searches to 168 predicted coding sequences (CDS) of the sequenced genomes listed above. Venn diagrams were 169 built using Venny (Oliveros 2007, http://bioinfogp.cnb.csic.es/tools/venny/index.html), based on 170 Elaeis guinnensis Blastn results, especially in cases where no arabidopsis counterpart was 171 identified.

172

173 Transcription factor sorting and analysis

174 Transcripts were further classified into overall functional categories as either metabolic 175 enzymes, mitochondrial, chloroplast, structural or regulatory, based on BLAST results.

176 Unknown transcripts as well as predicted uncharacterized transcripts were grouped as

177 "uncharacterized". Regulatory transcripts were further analyzed regarding their role as

178 transcription factors, and were subjected to further BLAST searches against the NCBI database, 179 based on their conserved DNA-binding amino-acid domains. Further analysis also entailed a 180 comparison of these transcripts to transcription factor sequences available at the curated plant 181 specific database PlantTFDB v4.0 (http://planttfdb.cbi.pku.edu.cn/index.php; Jin et al., 2013; 182 2017). A list of all transcription factors retrieved in this analysis is presented on Supplemental 183 Material S1.

184 All data processing was performed within the QB3 Computational Genomics Resource 185 Laboratory (CGRL) at University of California at Berkeley, except when specified otherwise. 


\section{Results}

188 Transcriptome assembly

189 The number of cleaned reads for each whole flower transcriptome ranged from $\sim 1$ million 190 reads for Costus spicatus to $142,860,349$ reads in Calathea zebrina (Table 2). The significant 191 difference in the number of reads is likely due to differences in the sequencing platform, in the 192 case of Co. spicatus, and unequal multiplexing of libraries, in the case of Ca. zebrina. All other 193 libraries resulted in a comparable number of reads, ranging form $\sim 4.3$ million in Orchidantha 194 fimbriata to $\sim 9.3$ million reads in Canna sp. The number of non-filtered contigs ranged from $195 \sim 52,000$ to $\sim 74,000$, except in Co. spicatus $(\sim 19,000)$ and Ca. zebrina $(\sim 132,000)$, likely due to 196 the discrepancy observed in the number of cleaned reads. With the exception of Co. spicatus, 197 contig average length and N50 were comparable in all other libraries (Table 2). It is interesting to 198 notice that, when compared to Zingiber officinale, a $\sim 35$-fold increase in the number of reads in 199 Ca. zebrina resulted in only a $\sim 2$-fold increase in contig length and N50. With the exception of 200 Co. spicatus and Ca. zebrina, all other species' best assemblies resulted in values for number of 201 contigs, N50 and average contig length (Table 2) comparable to those reported in the literature 202 (e.g., 75 medicinal plant transcriptomes in Xiao et al. 2013; Stevia rebaudiana transcriptome in 203 Chen et al. 2014; Musa acuminata root transcriptome in Zorrilla-Fontanesi et al. 2016).

204 In order to further assess assembly quality, we calculated RSEM-scores based on 205 estimates of true transcriptome length of Musa acuminata, Phoenix dactylifera, Elaeis 206 guineensis, and Arabidopsis thaliana (Table 2). Although we found no significant difference 207 between results, RSEM-EVAL scores tended to favor the largest transcript length (Elaeis 208 209 guineensis), regardless of phylogenetic proximity. Even for Musa basjoo, phylogenetically close

$\underline{\text { Transcriptome annotation and comparison }}$

212 Transcriptomes were filtered based not only on long predicted open reading frames (long 213 ORFs) but also on Blastp and HMMER3 results (filtered ORFs) using TransDecoder (Table 3). 214 The average number of filtered ORFs was $\sim 30,000$, ranging from 13,122 in Costus spicatus to 215 55,360 in Calathea zebrina. The number of filtered coding sequences observed in this study is 216 similar to already described numbers of floral unigenes of other non-model plants, which ranges 217 between $\sim 25,000$ (in buckwheat, Logacheva et al. 2011) to 80,000 (in Dendrocalamus latiflorus 
218 floral buds, Zhang et al. 2012). Whole flower transcriptome filtered ORFs represented on 219 average $47 \%$ of reconstructed contigs, and ranged from 40 to $68 \%$, similarly to what has been 220 recently reported in Arabidopsis developing flowers (23,961 expressed genes; 67\% of predicted

221 CDS; Zhang et al. 2015). After filtering, the high number of contigs observed in Calathea 222 zebrina was reduced to 55,360 ORFs, which is within the upper limits of already described non223 model plant floral transcriptomes (see above).

224 In order to further annotate the contigs, OrthoFinder was used to establish orthology

225 between the transcriptomes and the sequenced genome CDS. A total of 41,557 orthogroups were 226 found (Supplemental Material S2), of which 17,418 had counterparts in at least one of the 227 sequenced genomes included in the analysis. Over 24,000 groups had no CDS components in 228 any of the analyzed genomes, which might suggest the persistance of chimeras and/or truncated 229 ORFs within the filtered transcriptomes, Zingiberales specific genes, or a combination of the 230 two. Arabidopsis thaliana CDS were present in 11, 511 orthogroups (Supplemental Material S3), 231 while 5,907 orthogroups had no arabidopsis counterparts but comprised other CDS from at least 232 one of the other sequenced genomes. Orthogroup species overlap is presented on Table 4.

233 Furthermore, OrthoFinder identified 6,916 orthogroups with all 10 species present. Of those, 234 only 28 comprised single-copy orthogroups, in which one single ortholog was found for each 235 especies (Supplemental Material S4).

236 Within Zingiberales transcriptomes, the largest orthogroup overlap was to the Musa 237 acuminata genome, likely a reflection of their phylogenetic proximity. In all cases, Zingiberales 238 transcriptomes largest orthogroup overlap to a non-Zingiberales genome was to Elaeis 239 guineensis CDS.

240 One-hundred and forty-two (142) orthogroups were Arabidopsis thaliana-specific

241 (Supplemental Material S5) with no counterparts in any of the other analyzed genomes. Given

242 that all other genomes were from monocot species, this finding might reflect either Arabidopsis243 specific or eudicot-specific genes. Further analyses are necessary to determine whether these 244 genes are involved in eudicot- or arabidopsis-specific flower development.

245 Blastn searches were conducted on the basis of Arabidopsis, Elaeis, Phoenix and Musa

246 predicted CDS (Table 5). These searches produced variable results, potentially due to

247 phylogenetic proximity and degree of genome sequence completeness. In general, all floral 248 transcriptome Blastn searches resulted in a very small number of hits to Arabidopsis thaliana 
249 CDS, as expected due to its phylogenetic distance, indicating that although Arabidopsis is likely

250 the best annotated plant genome to date, its phylogenetic distance to the study group makes fine-

251 tuned statements of homology between Arabidopsis coding sequences and the predicted ORFs in

252 the Zingiberales species studied here a challenging task. For instance, while $80.5 \%$ of $M u s a$

253 acuminata CDS were present amongst Musa basjoo contigs, only 5\% of Arabidopsis thaliana

254 CDS were represented within the same assembly (Table 5), which is expected due to the nature

255 of Blastn searches. Only a small number of Blastn hits were observed for Phoenix dactylifera,

256 likely indicating incompleteness of the current genome sequence: $29 \%$ of Dichorisandra

257 thyrsiflora contigs matched Elaeis guineensis CDS, while the same contigs matched only $\sim 19 \%$

258 of Phoenix dactylifera CDS (Table 5). In order to avoid phylogenetic bias, as well as to

259 maximize transcriptome annotation, further Blastn analyses of filtered ORFs were based on

260 Elaeis guineensis predicted CDS.

261 Based on Blastn searches against Elaeis guineensis predicted CDS, floral transcriptomes

262 shared 4,153 genes (Figure 2). We also identified 1,748 hits specific to Zingiberales, 666 to the

263 ginger clade, 1,560 hits unique to the Cannaceae-Marantaceae lineage, 2,001 specific to the

264 banana families, and 1,887 specific to Zingiber officinale, from which 221 hits are shared with

265 Costus spicatus. The small number of contigs recovered for Costus spicatus likely limited the

266 analysis of the Costaceae-Zingiberaceae lineage-specific Blastn hits (Supplemental Material S6).

267

268 Conserved genes

269 Orthogroup analysis containing Arabidopsis thaliana counterparts (Supplemental

270 Material S3) revealed the presence of several well-known gene families in our flower

271 transcriptomes. Within these orthogroups, the most noticeable groups were members of the

272 AGAMOUS-like ( $A G L$ ) family of transcription factors, including $A G L 6, A G L 12, A G L 20, A G L 26$,

273 AGL29, AGL44, AGL58, AGL61, AGL65 and AGL104. Other MADS-box genes, widely

274 implicated in floral organ identity, were also identified such as APETALA3 (AP3), PISTALLATA

275 (PI), and SEPALLATA3 (SEP3). Other MADS-box gene families involved in flower and fruit

276 development were represented within the orthogroups: CAULIFLOWER $(C A L)$,

277 SHATTERPROOF2 (SHP2), CRABS CLAW (CRC), SHORT VEGETATIVE PHASE (SVP),

278 TRANSPARENT TESTA16 (TT16), FLOR1 (FLR1), BELL1 (BEL1), as well as several members

279 of the TCP/TEOSINTE BRANCHED family (TCP1, TCP3, TCP12, TCP15, and TCP24). 
280 Orthogroups lacking Arabidopsis thaliana counterparts further reinforced the presence of 281 AGAMOUS-like genes, such as $A G L 61, A G L 62$ (three orthogroups), $A G L 80$, as well as 282 MADS32 (O’Maoileidigh et al. 2014).

283 Blastn hits to E. guineensis were used to further place genes in functional categories, as 284 described in methods. Figure 3 depicts the main category of genes shared by all floral 285 transcriptomes. Almost half of these genes (47\%) are enzymes related to metabolic processes of 286 the cell, while $26 \%$ of the genes are structural proteins such as membrane proteins, cytoskeleton287 related proteins, ribosomal, histones, heat-shock and ribonucleoproteins. Approximately $10 \%$ of 288 these genes are regulatory proteins, of which approximately 508 could be assigned to known 289 transcription factor (TF) families, based on the PlantTFDB v4.0 (Supplemental Material S1). 290 From the 58 well-characterized plant transcription factor families, our dataset was able to 291 retrieve 36 families, based on the closest homolog in Arabidopsis thaliana (Table 6).

Additionally, 6 putative new categories of TFs that are not described in the database were 293 also recovered, although more experimental evidence is required to further categorize their 294 potential role as transcription factors. Here, we preliminarily named these sequences based on 295 their match to the NCBI Conserved Domain Dataset (https://www.ncbi.nlm.nih.gov/cdd): 296 Bromodomain-family (5 unique sequences: GTE4-like, GTE6-like, and GTE9-like homologs in 297 the Canna-Calathea clade; GTE7-like homologs in Zingiber officinale; and GTE9-like homologs 298 in Dichorisandra thyrsiflora); PUR-A family (1 unique sequence: PURA1-like homolog in the 299 Canna-Calathea clade); YL1 domain family (1 unique sequence: SWR1 complex subunit 2-like 300 homolog in Dichorisandra thyrsiflora); TFIIS-domain family (1 unique sequence: IWSI-like 301 homolog in Zingiber officinale); LIM-domain family (2 unique sequences: SEUSS-like 302 homologs in the banana clade) and SAND-domain family (1 unique sequence:

303 UTLRAPETALA1-like homolog in Zingiber officinale) (see Supplemental Material S1). 304 305 306 307 308

Interestingly, the remaining regulatory proteins that were not included in the transcription factor category were nonetheless implicated in regulating plant organ development and/or growth, acting as protein co-factors that physically interact with transcription factors, or as related to the chromatin remodeling machinery.

Among the transcription factors shared by all flower transcriptomes, it is worth noticing a single homolog of APETALA-2 (a member of the A-class ABC model genes (Jofuku et al. 1994)), three homologs of MADS-6 or AGL6, as well as several homologs of HUA2-like proteins 
3112 and 3. In Arabidopsis thaliana, HUA1 and HUA2 are important components of the AGAMOUS

312 gene regulation pathway (Chen \& Meyerowitz 1999). It has been suggested that HUA2 facilitates

313 AGAMOUS action during flower development (Chen \& Meyerowitz 1999), and it is also

314 required for the expression of FLC in Arabidopsis thaliana (Doyle et al. 2005). Moreover, HUA2

315 has been implicated in natural variation in Arabidopsis thaliana shoot morphology (Wang et a.

316 2007). Five $L E U N I G$-like homologs were also recovered in all floral transcriptomes. $L E U N I G$

317 proteins are also involved in the regulation of AGAMOUS expression in Arabidopsis thaliana

318 (Liu \& Meyerowitz 1995; Sridhar et al. 2004). The number of shared genes involved in the

319 regulation of $A G A M O U S$ indicates the shared importance of precise AGAMOUS regulation

320 during flower development (Supplemental Material S1). In particular, genes involved in

321 physiological responses to stress and pathogen response, such as the WRKY family of

322 transcription factors (Wang et al. 2011) and the NAC domain proteins (Nuruzzaman et al. 2013),

323 were recovered in all transcriptomes. More recently, WRKY71 has been implicated in the control

324 of shoot branching in Arabidopsis thaliana, through the regulation of $R A X$ genes (Guo et al.

325 2015). All floral transcriptomes also presented several members of the zinc-finger transcription

326 factor family, seven KNOTTED1-like homologs, as well as GATA transcription factors 2, 4, 12 ,

327 and 24. Several members of the bHLH family; homologs of MYB44, MYB82; TCP-4, -15, and -7

328 homologs; four CONSTANS-like homologs; several members of the TCP family, as well as

329 WUSHEL-like transcripts were also widely retrieved. (Supplemental Material S1).

330 Other regulatory proteins include, for example, a homolog of COBRA-like 1; two

331 homologs of FY-like proteins; one FRIGIDA-like homolog; and five homologs of EMBRYONIC

332 FLOWER2-like. We also retrieved six TOPLESS-like homologs, almost 20 members of the

333 TBC1 family, five IWS1 homologs, a GIGANTEA-like homolog, as well as four SQUAMOSA

334 PROMOTER BINDING-like homologs.

335 Interestingly, the most prominent feature of the Blastn searchers was the match to

336 different paralogues and/or variants of the same genes or gene families in different floral

337 transcriptomes (Supplemental Material S1). For example, LATERAL ORGAN BOUNDARIES

$338(L O B)$-domain homologs were retrieved in all floral transcriptomes analyzed. However, while

$339 L O B 40,41$ and 6-like homologs were retrieved in all Zingiberales floral transcriptomes, LOB36

340 and a paralog of $L O B 6$-like transcripts were retrieved only in the banana transcriptomes.

341 Similarly, LOB 18-like was only recovered in the Cannaceae-Marantaceae lineage, while LOB4- 
342 like transcript was only recovered in Zingiber officinale. On the other hand, LOB15-like

343 homologs were only recovered in the floral transcriptome of Dichorisandra thyrsiflora. $L O B$

344 genes have been implicated in defining organ boundaries in Arabidopsis floral organs through

345 negative regulation of brassinosteriod accumulation (Shuai et al. 2002; Bell et al. 2012).

346 Whether this phenomenon is a result of gene duplication followed by divergence or

347 whether it is due to lineage-specific divergence within a single copy begs further investigations.

348 Whether these homologs have retained the same function is an exciting matter for further studies.

$\underline{\text { Lineage-specific genes }}$

The great majority of lineage-specific genes, including Zingiberales specific genes, were

352 related to metabolic processes of the cells (Figure 3). The most prevalent unique genes were

353 enzymes such as oxidoreductases, methyltransferases, aminoacyl-tRNA synthetases, kinases, hydrolases, and phosphatases. Carrier proteins, transporters, chaperones and ribonucleoproteins were also abundant in all lineage-specific datasets. Several transcription factors, many of which are known players during plant development, were recovered in a lineage-specific fashion. Fifty percent of Zingiberales specific genes are metabolic enzymes (28\%) or structural proteins (22\%), while $12 \%$, approximately 210 coding sequences, are regulatory proteins (Figure 3 ).

Among these regulatory proteins, several families of transcription factors were recovered exclusively in the Zingiberales, such as ENHANCER OF AG-4, various AP2-like ethyleneresponse transcription factors, BRZ1 homologs 1 and 3, SHOOT GRAVITROPISM 5-like homolog, the zinc-finger transcription factor $J A C K D A W$-like homolog, a $Y A B B Y 2$-like homolog, as well as $G T-2$ and $G T-3$ (GT-element binding transcription factors) homologs. ginger groups transcriptomes. Similarly, other homologs appeared in a lineage-specific manner. For example, while two homologs of B-ZIP transcription factor family TGA4-like were recovered in the banana group, homologs for TGA2-like were recovered only in the ginger clade. Likewise, homologs of the trihelix DNA binding family gene ASIL1-like (ARABIDOPSIS 6BINTERACTING PROTEIN 1-LIKE) were recovered in the banana group, while ASIL2-like homologs were recovered in the ginger clade. 
373 homeodomain (PHD) protein ING2 (Inhibitor of growth). ING tumor suppressors are found in

374 animals, plants and yeast, and have long been implicated in oncogenesis, control of DNA

375 damage repair, cellular senescence and apoptosis (Champagne \& Kutateladze 2009). In $A$.

376 thaliana, ING2 is involved in chromatin regulation by binding to the active histone marker

377 H3K4me3/2 (Lee et al. 2009). Histone modifications, such as those promoted by ING2 and other

378 PHD proteins, modulate the expression of crucial genes involved in flower development (López-

379 González et al. 2014). Similarly, the histone chaperone ANTI-SILENCING FACTOR-1 (ASF1)

380 homologue was recovered in all analyzed Zingiberales transcriptomes, while missing in

381 Dichorisandra thyrsiflora. ASF1 is a family of histone chaperones conserved in all eukaryotes

382 (Tripathi et al. 2015), and in A. thaliana ASF1 is required for cell proliferation during

383 development and is involved in transcriptional regulation of histones and histone modifications

384 (Zhu et al. 2011). However interesting, further analyses are necessary to establish the potential

385 role of histone modifications, and in particular the functions of ING2 and ASF1, in Zingiberales

386 flower development.

387 In turn, various transcription factors were only recovered in the Dichorisandra thyrsiflora

388 floral transcriptome to the exclusion of the Zingiberales. Among these are a

389 FLORICAULA/LEAFY homolog, a homolog of ODORANT1-like, a homolog of

$390 J U N G B R U N N E N$ 1-like, homologs of $R A X-1,-2$, and -3, as well as homologs of the transcription

391 factors $D P B, T T 2$-like, and GAMYB-like. In particular, a SOMBRERO-like homolog was

392 retrieved only in Dichorisandra thyrsiflora. SOMBRERO proteins, members of the NAC

393 domain transcription factors, have been implicated in the control of cell division plane

394 orientation in Arabidopsis thaliana (Wllemsen et al. 2008). Other regulators retrieved

395 specifically in the Dichorisandra lineage include two STICHEL-like homologs, a homolog of

396 UPSTREAM OF FLC-like, a TONSOKU-like homolog, two SAGA-like homologs, a

397 TASSELSEED homolog, and a TITAN-like homolog.

398 Regulatory sequences retrieved exclusively within the banana lineage, represented by

399 Musa basjoo and Orchidantha fimbriata floral transcriptomes, include four CCAl-like

400 homologs, six FLX2-like homologs, a KTI12-like homolog, a YABBY4-like homolog, a CPC

401 homolog, and a SPATULA homolog represent transcription factors that were recovered

402 exclusively in this group. Curiously, few coding sequences were uniquely reconstructed

403 within the ginger clade, potentially due to the low coverage of the Costus spicatus transcriptome. 
404 Particularly interesting is the unique recovery of four AS1-like (ASYMMETRIC LEAVES-1)

405 homologs and two DROOPING LEAF-like genes. Regulatory coding sequences uniquely

406 reconstructed in the Canna-Calathea (Cannaceae-Marantaceae) lineage include a CUC2

407 homolog, a homolog of Arabidopsis EXORDIUM-like protein, two FAF-like homologs, and five 408 SPX-like homologs.

409 A complete list of lineage specific transcription factors, sorted by plant transcription

410 factor families characterized in the PlantTFDB, can be found in Supplemental Material S1.

412 Discussion

413 Recently, there has been an explosion in the use of RNA-Seq approaches as part of a 414 comparative analysis pipeline to study the evolution of developmental processes, using plant 415 transcriptomes as an indication of differential gene expression among organisms with different 416 phenotypic displays. This approach has become particularly important in non-model organisms 417 that lack a reference genome or other genetic and bioinformatic tools that exist in plant model 418 organisms like A. thaliana, rice, poplar or corn. Despite challenges assembling transcriptomic 419 sequence data without a reference genome, researchers can determine the quality of their data 420 based on the number, size and scores of the contigs assembled. The transcriptome data presented 421 here are in agreement in terms of number of contigs, contig size distributions, and quality scores 422 with those presented in the literature.

423 The study of mechanisms underlying floral diversification in plant lineages will likely 424 point, in most cases, to at least three potentially concurrent scenarios: (i) tinkering of conserved 425 mechanisms specific to flower development; (b) evolution of lineage-specific mechanisms 426 resulting in novelty or change, or (c) co-option of non-flower mechanisms to elaborate specific 427 aspects of flower development. The identification of these mechanisms, however, requires 428 careful examination of exemplar species within a clearly delimited phylogenetic context. Also, 429 careful choice of outgroup species might help the distinction between gain versus loss of 430 molecular processes when analyzing lineage specific phenomena. Our data show that the 431 inclusion of Dichorisandra thyrsiflora significantly reduced the overall number of Zingiberales 432 unique genes, as well as the number of lineage specific genes within the Zingiberales, potentially 433 due to shared molecular mechanism during flower development. It is possible that the addition of 434 other outgroups would further limit the lineage-specific datasets. The results presented here 
435 support previous assertions that annotation based on Blastn searches is highly influenced by

436 phylogenetic proximity as well as genome sequence completeness and annotation quality,

437 particularly when blasting against predicted CDS (Hornett and Wheat 2012). Meanwhile,

438 orthogroup analysis provides a wider view of less stringent relationships between trasncriptomes.

439 Furthermore, the orthogroup analysis presented here reinforces the notion that gene duplications

440 are a widespread phenomenon during plant evolution (Panchy et al 2016). Only 28 of the over

44140,000 orthogroups identified comprised single copy genes in the transcriptomes and genomes 442 analyzed.

443 The stringent filtering of the data performed with Blastn likely excluded several genes

444 that could potentially participate in flower development across the Zingiberales and in the 445 outgroup (D. thyrsiflora), and may even participate in floral evolution. However, due to this 446 stringent cutoff, it is likely that the genes recovered are strong candidates for further studies.

447 Functional analysis of the genes that emerge from these comparative datasets, coupled with 448 careful phylogenetic assessments of specific gene families, will potentially refine the picture.

449 Perhaps the most significant results presented here relate to the set of shared floral 450 transcription factors recovered for all taxa analyzed. Due to the nature of the methodology used, 451 we believe there is sufficient evidence to support the presence of these genes in all floral 452 transcriptome studies, making them likely floral development regulators and involved in not only 453 floral development but, given their presence among and between lineages, suggesting that they 454 are conserved regulators of floral evolution. Most of these genes and gene families have already 455 been implicated in floral development in A. thaliana, but knowledge of their roles outside core 456 eudicots is still poor. Their specific involvement in processes of morphological diversification 457 has yet to be established.

458 Our results point to interesting differences between Zingiberales lineages. In particular, 459 the presence of a $Y A B B Y 4$-like homolog in the banana lineages but not in the ginger clade 460 where only a $Y A B B Y 2$-like homolog was reconstructed - might underlie developmental 461 differences between these Zingiberales flowers. Information regarding the role of $Y A B B Y 4$ in 462 comparative floral development remains sparse. Even though expression of YABBY4 (INNER NO 463 OUTER) is restricted to the ovule integument (Villanueva et al. 1999) and seems to be conserved 464 across angiosperms (Skinner et al. 2016), little is known about the presence of this gene in 465 monocots other than rice, or pertaining the role it may play in ovule development within the 
466 monocot clade (Toriba et al. 2007; Morioka et al. 2015). Although it requires further evidence, 467 the lineage specific gene set presented here might provide an interesting candidate gene list for 468 further studies into the molecular mechanisms of floral development and diversification in the 469 Zingiberales.

470 It is widely accepted that the ability to recover low expressed genes is related to 471 transcriptome coverage (Grabherr et al. 2011; Martin \& Zhang 2011; Tarazona et al. 2011). The

472 high coverage of Calathea might explain the large number of genes recovered that appear unique 473 to Cannaceae-Marantaceae, especially given the overrepresentation of transcription factors in 474 this lineage. However, the total number of unique transcription factors between Canna and 475 Calathea is similar to that observed in other lineages within the Zingiberales. Particularly 476 interesting was the reconstruction of CUP-SHAPED COTYLEDON2 (CUC2) exclusively in the 477 Cannaceae-Marantaceae lineage. The evolution and functional divergence of CUC genes (1-3) 478 have been well studied in Arabidopsis (Hasson et al. 2011), although much less is known in 479 monocots especially outside of the grasses. During flower development, CUC genes have been 480 implicated in the formation of carpel margin meristems, although their role in plant development 481 does not appear to be restricted to the flower (Kamiuchi et al. 2014). It is conceivable that the $482 C U C$ gene copies play important roles, together with SPATULA homologs (SPT) (Nahar et al. 483 2012), in carpel diversification in Zingiberales.

$484 \quad$ It is interesting to notice that $A G A M O U S$ regulatory proteins were widely recovered in all 485 transcriptomes, suggesting consistent levels of expression throughout the Zingiberales and 486 outgroup developing flowers. This might support the evolution of several regulatory mechanisms 487 of $A G A M O U S$ expression during flower development, bringing redundancy and indicating the 488 critical nature of $A G A M O U S$ regulation. In turn, it may suggest that variations of $A G A M O U S$ 489 expression might lead to floral morphological diversification, a mechanism that has already been 490 proposed to participate in Zingiberales flower evolution (Almeida et al. 2015b).

491 Because expression levels can interfere with the ability to reconstruct specific genes, it is 492 possible that some of the differences observed in lineage-specific transcriptome reconstructions, 493 particularly the absence of transcripts, are due to low or restricted expression within the 494 developing flower. It is imperative that further studies are carried out, especially comparative 495 spatial-temporal expression studies, to further unravel the role of these transcription factors in 496 floral morphological variation. Comparisons based on expression levels of shared genes, as well 
497 as protein-protein or protein-DNA interactions, can certainly reveal other levels of

498 developmental divergence. Expression levels were not calculated here, due to the lack of

499 replicates for each floral transcriptome. Also, despite the interesting findings discussed here

500 regarding coding sequences and, in particular transcription factors, further analysis is needed to

501 fully uncover the mechanisms underlying floral developmental evolution. A careful analysis of

502 non-coding sequences might revel other layers of gene regulation and function that were not

503 explored in this work. The complexity of the molecular mechanisms underlying floral

504 development cannot be underestimated. Thus, we believe that further investigations are needed

505 to achieve a full understanding of the molecular processes underlying flower developmental

506 evolution in the Zingiberales.

507 Despite limitations, we believe the transcriptome analysis presented here sheds light on

508 interesting phenomena that might underlie molecular mechanisms of flower developmental

509 evolution. In particular, the consistent recovery of distinct homologs for various genes families

510 in closely related evolutionary lineages is a pattern that suggests the need for further studies. The

511 complex patterns of gene duplications in plants, although daunting, provides an exciting

512 opportunity for the study of the relationship between genes, functions and morphological

513 diversification.

514

\section{Acknowledgements}

516 The authors would like to acknowledge H.Forbes from UC Botanical Garden, and

517 E.Sandoval from UC Davis Greenhouses for support with plant materials; K.Bi from qB3

518 Computational Genomics Lab (UC Berkeley) for help with data processing and L.Smith from the 519 Evolutionary Genetics Lab (UCB) for support during library preparations.

520

521 References

522

523 Almeida AMR, Yockteng R, Schnable J, Alvarez-Buylla ER, Freeling M and Specht CD. 2014.

524 Co-option of the polarity gene network shapes filament morphology in angiosperms. Nature

525 Scientific Reports, 4.

526 
527 Almeida, AMR.; Yockteng, R.; Specht, CD. 2015a. Evolution of petaloidy in the Zingiberales:

528 an assessment of the relationship between ultrastructure and gene expression patterns.

529 Developmental Dynamics, 244: 1121-1132.

530

531 Almeida AMR, Yockteng R, Otoni WC, Specht CD. 2015b. Positive selection on the K domain 532 of the AGAMOUS protein in the Zingiberales suggests a mechanism for the evolution of 533 androecial morphology. BMC EvoDevo, 6(7), DOI: 10.1186/s13227-015-0002-x.

534

535 Al-Mssallem, I.; Hu, S.; Zhang, X.; Lin, Q.; Liu, W.; Tan, J.; Yu, X.; Liu, J.; Pan, L.; Zhang, T.; 536 Yin, Y.; Xin, C.; Wu, H.; Zhang, G.; Abdullah, M.M.B.; Huang, D.; Fang, Y.; Alnakhli, Y.O.;

537 Jia, S.; Yin, A.; Alhuzimi, E.M.; Alsaihati, B.A.; Al-Owayyed, S.A.A.; Zhao, D.; Zhang, S.; Al-

538 Otaibi, N.A.; Sun, G.; Majrashi, M.A.; Li, F.; Wang, J.; Yun, Q.; Alnassar, N.A.; Wang, L.;

539 Yang, M.; Al-Jelaify, R.F.; Liu, K.; Gao, S.; Chen, K.; Alkhaldi, S.R.; Liu, G.; Zhang, M.; Guo, 540 H.; Yu, J. 2013. Genome sequence of the data palm Phoenix dactylifera L. Nature

541 Communications, 4(2274), DOI: 10.1038/ncomms3274.

542

543 Bartlett, M.; Specht, C.D. Evidence for the involvement of GLOBOSA-like gene duplications

544 and expression divergence in the evolution of floral morphology in the Zingiberales. 2010. New 545 Phytologist, 187:521-541.

546

547 Bell, EM.; Lin, WC.; Husbands, AY.; Yu, L.; Jagantha, V.; Jablonska, B.; Mangeon, A.; Neff, 548 MM.; Girke, T.; Springer, PS. 2012. Arabidopsis lateral organ boundaries negatively regulated 549 brassinosteroid acumination to limit growth in organ boundaries. PNAS, 109: 21146-51.

550

551 Bolger, A. M.; Lohse, M.; Usadel, B. 2014. Trimmomatic: A flexible trimmer for Illumina 552 Sequence Data. Bioinformatics, DOI: 10.1093/bioinformatics/btu170.

553

554 Casimiro-Soriguer, I.; Narbona, E.; Buide, ML.; Valle, JCD.; Whitall, JB. 2016. Transcriptome 555 and biochemical analysis of a flower color polymorphism in Silene littorea (Caryophyllaceae).

556 Frontiers in Plant Science, 7: 204, DOI: 10.3389/fpls.2016.00204. 
558 Champagne, KS.; Kutateladze, TG. 2009. Structural insight into histone recognition by the ING

559 PHD fingers. Current Drug Targets, 10(5): 432-441.

560

561 Chanderbali, AS.; Albert, VA.; Leebens-Mack, J.; Altman, NS.; Soltis, DE.; Soltis, PS. 2009.

562 Transcriptional signatures of ancient floral developmental genetics in avocado (Persea

563 Americana; Lauraceae). PNAS, 106(22): 8929-8934.

564

565 Chanderbali, AS.; Yoo, M-J.; Zahn, LM.; Brockington, SF.; Wall, PK.; Gitzendanner, MA.;

566 Albert, VA.; Leebens-Mack, J.; Altman, NS.; Ma, H.; dePamphilis, CW.; Soltis, DE.; Soltis, PS.

567 2010. Conservation and canalization of gene expression during angiosperm diversification

568 accompany the origin and evolution of the flower. PNAS, 107(52): 22570-22575.

569

570 Chen, J.; Hou, K.; Qin, P.; Liu, H.; Yi, B.; Yang, W.; Wu, W. 2014. RNA-seq for gene

571 identification and transcript profiling of three Stevia rebaudiana genotypes. BMC Genomics, 15 :

572571.

573

574 Chen, X.; Meyerowitz, EM. 1999. HUA1 e HUA2 are two members of the floral homeotic

575 AGAMOUS pathway. Molecular Cell, 3(3):349-360.

576

577 Chiara, M.; Horner, DS.; Spada, A. 2013. De Novo Assembly of the Transcriptome of the Model

578 Plant Streptocarpus rexii Employing a Novel Heuristic to recover Locus-Specific Transcript

579 CLustes. PLOS ONE 8, 12: e80961.

580

581 Davila-Velderrain, J.; Servin-Marquez, A.; Alvarez-Buylla, ER. 2013. Molecular Evolutin

582 Constraints in the Floral Organ Specification Gene Regulatory Network Module across 18

583 Angiosperm Gneomes. Molecular Biology and Evolution, DOI:10.1093/molbev/mst223.

584

585 Deng, N.; Chang, E.; Li, M.; Ji, J.; Yao, X.; Bartish, IV.; Liu, J.; Ma, J.; Chen, L.; Jiang, Z.; Shi,

586 S. 2016. Transciptome characterization of Gnetum parvifolium reveals candidate genes involved

587 in important secondary metabolic pathways of flavonoids and stilbenoids. Frontiers in Plant

588 Science, 7: 174, DOI: 10.3389/fpls.2016.00174. 
590 D’Hont, A.; Denoeud, F.; Aury, J-M.,; Baurens, F-C.; Carreel, F.; Garsmeur, O.; Noel, B.; Bocs, 591 S.; Droc, G.; Rouard, M.; Silva, Cd.; Jabbari, K.; Cardin, C.; Poulain, J.; Souquet, M.; Labadie, 592 K.; Jourda, C.; Lengellé, J.; Rodier-Goud, M.; Alberti, A.; Bernand, M.; Correa, M.; 593 Ayyampalayam, S.; Mckain, MR.; Leebens-Mack, J.; Burguess, D.; Freeling, M.; Mbéguié-A594 Mbéguié, D.; Chabannes, M.; Wicker, T.; Panaud, O.; Barbosa, J.; Hribova, E.; Heslop-Harrison, 595 P.; Habas, R.; Rivallan, R.; Francoi, P.; Poiron, C.; Kilian, A.; Burthia, D.; Jenny, C.; Bakry, F.; 596 Brown, S.; Guignon, V.; Kema, G.; Dita, M.; Waalwijk, C.; Joseph, S.; Dievart, A.; Jaillon, O.; 597 Leclercq, J.; Argout, X.; Lyons, E.; Almeida, A.; Jeridi, M.; Dolezel, J.; Roux, N.; Risterucci, A598 M.; Weissenbach, J.; Ruiz, M.; Glaszmann, J-C.; Quétier, F.; Yahiaoui, N.; Wincker, P.; 2012. 599 The banana (Musa acuminata) genome and the evolution of monocotyledonous plants. Nature, 600 488: 213-219, DOI: 10.1038/nature11241.

601

602 Doyle, MR.; Bizzell, CM.; Keller, MR.; Michaelis, SD.; Song, J.; Noh, YS.; Amasino, RM. 603 2005. HUA2 is required for the expression of floral repressors in Arabidopsis thaliana. Plant 604 Journal, 41(3): 376-385.

605

606

Eddy, SR. 1998. Profile hidden Markov models. Bioinformatics, 14(9): 755-763.

607

608 Finn, R.D. ; Coggill, P.; Eberhardt, R.Y.; Eddy, S.R. ; Mistry, J.; Mitchell, A.L.; Potter, S.C.;

609 Punta, M.; Qureshi, M.; Sangrador-Vegas, A.; Salazar, G.A.; Tate, J.; Bateman, A. 2016. The 610 Pfam protein families database: towards a more sustainable future. Nucleic Acids Research, 611 44:D279-D285.

612

613 Gish, W.; States, D.J. 1993. Identification of protein coding regions by database similarity 614 search. Nature Genetics, 3:266-272.

615

616 González-Plaza, JJ.; Ortiz-Martin, I.; Muñoz-Mérida, A.; Garcia-López, C.; Sánchez-Sevilla, JF.; 617 Luque, F.; Trelles, O.; Bejarano, ER.; Rosa, RDL.; Valpuesta, V.; Beuzón, CR. 2016.

618 Transcriptomic analysis using olive varieties and breeding progenies indentifies candidate genes 619 involved in plant architecture. Frontiers in Plant Science, 7: 240, DOI: 10.3389/fpls.2016.00240. 
620

621 Grabherr, M.G.; Haas, B.J.; Yassour, M.; Levin, J.Z.; Thompson, D.A.; Amit, I.; Adiconis, X.; 622 Fan, L.; Raychowdhury, R.; Zeng, Q.; Chen, Z.; Mauceli, E.; Hacohen, N.; Gnirke, A.; Rhind, 623 N.; di Palma, F.; Birren, B.W.; Nusbaum, C.; Lindblad-Toh, K.; Friedman, N.; Regev, A. Full624 length transcriptome assembly from RNA-seq data without a reference genome. Nature 625 Biotechnology 2011, 29: 644-652.

626

627 Guo, D.; Zhang, J.; Wang, X.; Wei, B.; Wang, J.; Li, B.; Yu, H.; Huang, Q.; Gu, H.; Qu, L-J.; 628 Qin, J. 2015. The WRKY transcription factor WRKY71/EXB1 controls shoot branching by 629 transcriptionally regulating RAX genes in Arabidopsis. The Plant Cell, 630 http://www.plantcell.org/content/27/11/3112.

631

632 Hasson, A.; Plessis, A.; Blein, T.; Adroher, B.; Grigg, S.; Tsiantis, M.; Boudaoud, A.; Demerval, 633 C.; Laufs, P. 2011. Evolution and Diverse roles of the CUP-SHAPED COTYLEDON genes in 634 Arabidopsis leaf development. The Plant Cell, 23(1): 54-68.

635

636 Hollender, CA.; Kang, C.; Darwish, O.; Geretz, A.; Matthews, BF.; Slovin, J.; Alkharouf, N.; 637 Liu, Z. 2014. Floral Transcriptomes in Woodland Strawberry Uncover Developing Receptacle 638 and Anther Gene Networks. Plant Physiology, 165: 1062-1075.

639

640 Hornett, E.A.; Wheat, C.W. 2012. Quantitative RNA-seq analysis in non-model species:

641 assessing transcriptome assemblies as a scaffold and the utility of evolutionary divergent 642 genomic reference species. BMC Genomics, 13: 361, http://www.biomedcentral.com/1471$6432164 / 13 / 361$.

644

645 Jofuku, KD.; de Boer, BG.; Montagu, MV.; Okamuro, JK. 1994. Control of Arabidopsis flower 646 and seed development by the homeotic gene APETALA2. The Plant Cell, 6(9): 1211-1225. 647

648 Kamiuchi, Y.; Yamamoto, K.; Furutani, M.; Tasaka, M.; Aida, M. 2014. The CUC1 and CUC2 649 genes promote carpel margin meristem formation during Arabidopsis gynoecium development. 650 Frontiers in Plant Science, 5: 165, doi: 10.3389/fpls.2014.00165. 
651

652 Kent, W.J. 2002. BLAT-the BLAST-like alignment tool. Genome Research, 12:656-664.

653

654 Langmead, B.; Trapnell, C.; Pop, M.; Salzberg, S.L. 2009. Ultrafast and memory-efficient

655 alignment of short DNA sequences to the human genome. Genome Biol 2009, 10:R25.

656

657 Lee, WY.; Lee, D.; Chung, W-II.; Kwon, CS. 2009. Arabidopsis ING and Alfin1-like protein

658 families locate to the nucleus and bind to $\mathrm{H} 3 \mathrm{~K} 4 \mathrm{me} 3 / 2$ via plant homeodomain fingers. The Plant

659 Journal, 58: 511-524.

660

661 Li, B.*; Fillmore, N.*; Bai, Y; Collins, M.; Thomson, J.A.; Stewart, R.; Dewey, C.N. 2014.

662 Evaluation of de novo transcriptome assemblies from RNA-Seq data. Genome Biology, 15:553,

663 DOI: $10.1186 / \mathrm{s} 13059-014-0553-5$. * These authors contributed equally to this publication.

664

665 Liu, Z.; Meyerowitz, EM. 1995. LEUNIG regulates AGAMOUS expression in Arabidopsis

666 flowers. Development, 121: 975-991.

667

668 Logacheca, MD.; Kasianov, AS.; Vinogradov, DV.; Samigullin, TH.; Gelfand, MS.; Makeev,

669 VJ.; Penin, AA. 2011. De novo sequencing and characterization of floral transcriptome in two

670 species of buckwheat (Fagopyrum). BMC Genomics, 12: 30.

671

672 López-González, L.; Mouriz, A.; Narro-Diego, L.; Bustos, R.; Martínez-Zapater, M.; Jarillo, JA.;

673 Piñeiro, M. 2014. Chromatin-dependent Repression of the Arabidopsis Floral Integrator Genes

674 Invovles Plant Specific PHD-Containing Proteins. The Plant Cell, 26: 3922-3938.

675

676 Martin, M. 2011. Cutadapt removes adapter sequences from high-throughput sequencing reads.

677 EMBnet Journal, 17: 10-12.

678

679 Martin, JA.; Wang, Z. 2011. Next-generation transcriptome assembly. Nature Reviews Genetics, 680 12:671-682.

681 
682 Morioka, K.; Yockteng, R.; Almeida, AMR.; Specht, CD. 2015. Loss of YABBY2-like gene 683 expression may underlie the evolution of the laminar style in Canna and contribute to floral 684 morphological diversity in the Zingiberales. Frontiers in Plant Science, doi:

$68510.3389 /$ fpls.2015.01106.

686

687 Nahar, MA.; Ishida, T.; Smyth, DR.; Tasaka, M.; Aida, M. 2012. Interactions of CUP-SAPED 688 COTYLEDON and SPATULA genes control carpel margin development in Arabidopsis 689 thaliana. Plant Cell Physiology, 53(6): 1134-43.

690

691 Nuruzzaman, M.; Sharoni, AM.; Kikuchi, S. 2013. Roles of NAC transcription factors in the 692 regulation of biotic and abiotic stress responses in plants. Frontiers in Microbiology, doi:

$69310.3389 /$ fmicb.2013.00248.

694

695 Oliveros, J.C. 2007-2015. Venny. An interactive tool for comparing lists with Venn's diagrams.

696 http://bioinfogp.cnb.csic.es/tools/venny/index.html

697

698

O’Maoileidigh, DS; Graciet, E; Wellmer, F. 2014. Gene Networks controlling Arabidopsis 699 thaliana flower development. New Phytologist, doi: 10.1111/nph.12444.

700

701

702

Panchy, N; Lehti-Shiu, M; Shiu, S-H. 2016. Evolution of gene duplication in plants. Plant Physiology, doi: 10.1104/pp.16.00523.

703

704 Sass, C.; Iles, W.J.D.; Barret, C.F.; Smith, S.Y.; Specht, C.D. 2016. Revisiting the Zingiberales:

705 using multiplexed exon capture to resolve ancient and recent phylogenetic splits in a charismatic 706 plant lineage. Peer J., 4:e1584. DOI 10.7717/peerj.1584.

707

708 Singh, R.; Ong-Abdullah, M.; Leslie, E-T.; Low, L.; Arif, M.; MAnaf, A.; Rosli, R.; Nookiah, 709 R.; Ooi, L.C-L.; Ooi, S-E.; Chan, K-L.; Halim, M.A.; Azizi, N.; Nagappan, J.; Bacher, B.;

710 Lakey, N.; Smith, S.W.; He, D.; Hogan, M.; Budiman, M.A.; Lee, E.K.; DeSalle, R.; Kudrna, D.;

711 Goicoechea, J.L.; Wing, R.A.; Wilson, R.K.; Fulton, R.S.; Ordway, J.M.; Martienssen, R.A.; 
712 Sambanthamurthi, R. 2013. Oil plam genome sequence reveals divergence of interferitle species

713 in Old and New wolrds. Nature, 500: 335-339, DOI: 10.1038/nature12309.

714

715 Singhal, S. 2013. De novo transcriptome analyses for non-model organisms: an evaluation of 716 methods across a multi-species dataset. Molecular Ecology Resources, 13: 403-416.

717

718 Shuai, B.; Reynaga-Peña, CG.; Springer, PS. 2002. The lateral organ boundaries gene defines a 719 novel, plant specific gene family. Plant Physiology, 129: 747-761.

720

721 Skinner, DJ.; Brown, RH.; Kuzoff, RK.; Gasser, CS. 2016. Conservation of the role of INNER

722 NO OUTER in development of unitegmic ovules of the Solanaceae despite a divergence in 723 protein function. BMC Plant Biology, 16: 143, doi: 10.1186/s12870-016-0835-z.

724

725 Sridhar, VV.; Surendrarao, A.; Gonzalez, D.; Conlan, RS.; Liu, Z. 2004. Transcriptional

726 repression of target genes by LEUNIG and SEUSS, two interacting regulatory proteins for

727 Arabidopsis floral development. PNAS, 101(31): 11494-11499.

728

729 Tarazona, S.; García-Alcade, F.; Dopazo, J.; Ferrer, A.; Conesa, A. 2011. Differential expression 730 in RNA-Seq: a matter of depth. Genome Research, 21(12): 2213-2223.

731

732 The Arabidopsis Genome Initiative. 2000. Analysis of the genome sequence of the flowering 733 plant Arabidopsis thaliana. Nature, 408: 796-815.

734

735 The UniProt Consortium. 2015. UniProt: a hub for protein information. Nucleic Acids Research, 736 43: D204-D212.

737

738 Toriba, T.; Harada, K.; Takamura, A.; Nakamura, H.; Ichikawa, H.; Suzaki, T.; Hirano, H-Y. 739 2007. Molecular characterization of the YABBY gene family in Oryza sativa and expression 740 analysis of OsYABBY1. Molecular Genetics and Genomics 277: 457-468. 
742 Triphathi, AK.; Singh, K.; Pareek, A.; Singla-Pareek, SL. 2015. Histone chaperones in

743 Arabidopsis and rice: genome-wide identification, phylogeny, architecture, and transcriptional

744 regulation. BMC Plant Biology, 15: 42, DOI: 10.1186/s12870-015-0414-8.

745

746 Unamba, CIN.; Nag, A.; Sharma, RK. 2015. Next Generation Sequencing Technologies: The

747 Doorway to the Unexplored Genomics of Non-Model Plants. Frontiers in Plant Science, 6. DOI:

$74810.3389 /$ fpls.2015.01074.

749

750 Villanueva, J.; Bradhvest, J.; Hauser, BA.; Meister, RJ.; Schneitz, K.; Gasser, CS. 1999. INNER

751 NO OUTER regulates abaxial-adaxial patterning in Arabidopsis ovules. Genes \& Development, 752 13(23): 3160-3169.

753

754 Wang, Q.; Sajja, U.; Rosloski, S.; Humphrey, T.; Kim, MC.; Bomblies, K.; Weigel, D.; Grbic, V. 755 2007. HUA2 caused natural variation in shoot morphology of Arabidopsis thaliana. Current 756 Biology, 17(17): 1513-1519.

757

758 Wang, Q.; Wang, M.; Zhang, X.; Hao, B.; Kaushik, SK.; Pan, Y. 2011. WRKY gene family 759 evolution in Arabidopsis thaliana. Genetica, 139:973.

760

761 Wang, Z.; Gerstein, M.; Snyder, M. 2009. RNA-Seq: a revolutionary tool for transcriptomics.

762 Nature Reviews Genetics, 10: 57-63.

763

764 Wit, PD.; Pespeni, MH.; Ladner, JT.; Barshis, DJ.; Seneca, F.; Jaris, H.; Therkildsen, NO.;

765 Morikawa, M.; Palumbi, SR. 2012. The simple fool's guide to population genomics via RNA-

766 Seq: an introduction to high-throughput sequencing data analysis. Molecular Ecology Resources, 767 12:1058-1067. DOI: 10.1111/1755-0998.12003.

768

769 Xiao, M.; Zhang, Y.; Chen, X.; Lee, E-J.; Barber, C.J.; Chakrabarty, R.; Desgagné-Penix, I.;

770 Haslam, T.M.; Kim, Y.B.; Liu, E.; MacNevin, G.; Masada-Atsumi, S.; Reed, D.W.; Stout, J.M.;

771 Zerbe, P.; Zhang, Y.; Bohlmann, J.; Covello, P.S.; De Luca, V.; Page, J.E.; Ro, D.K.; Martin,

772 V.J.; Facchini, P.J.; Sensen, C.W. 2013. Transcriptome analysis based on next-generation 
773 sequencing of non-model plants producing specialized metabolites of biotechnological interest.

774 Journal of Biothecnology, 166: 122-134.

775

776 Yao, Q-Y.; Huang, H.; Tong, Y.; Xia, E-H.; Gao, L-Z. 2016. Transcriptome analysis indentifies

777 candidate genes related to triacylglycerol and pigment biosynthesis and photoperiodic flowering

778 in the ornamental and oil-producing plant, Camellia reticulata (Theaceae). Frontiers in Plant

779 Science, 7: 163, DOI: 10.3389/fpls.2016.00163.

780

781 Yockteng RB, Almeida AMR, Morioka K, Alvarez-Buylla ER and Specht CD. 2013a. Molecular

782 evolution and patterns of duplications in the SEP/AGL6-like lineage of the Zingiberales: a

783 proposed mechanism for floral diversification. Molecular Biology and Evolution, DOI:

$784 \quad 10.1093 / \mathrm{molbev} / \mathrm{mst} 137$.

785

786 Yockteng, R.; Almeida, A.M.R.; Yee, S.; Andre, T.; Hill, C.; Specht, C.D. 2013b. A method for 787 extracting high-quality RNA from diverse plants for next-generation sequencing and gene 788 expression analyses. Applications in Plant Science, 1: 1300070.

789

790 Zhang, L.; Wang, L.; Yang, Y.; Cui, J.; Chang, F.; Wang, Y.; Ma, H. 2015. Analysis of

791 Arabidopsis floral transcriptome: detection of newly florally expressed gene and expansion of

792 Brassicaceae-specific gene families. Frontiers in Plant Science, 5: 802, DOI:

$79310.3389 /$ fpls.2014.00802.

794

795 Zhang, X-M.; Zhao, L.; Larson-Rabin, Z.; Li, D-Z.; Guo, Z-H. 2012. De Novo Sequencing and 796 Characterization of the Floral Transcriptome of Dendrocalamus latiflorus (Poaceae:

797 Bambusoideae). PLoS ONE, 7(8): e42082. DOI: 10.1371/journal.pone.0042082.

798

799 Zhang, X.; Liu, T.; Duan, M.; Song, J.; Li, X. 2016. De novo transcriptome analysis of Sinapis 800 alba in revealing the glucosinate and phytochelatin pathways. 2016. Frontiers in Plant Science, 7: 801 259, DOI: 10.3389/fpls.2016.00259.

802 
803 Zhu, Y.; Weng, M.; Yang, Y.; Zhang, C.; Li, Z.; Shen, W-H.; Dong, A. 2011. Arabidopsis 804 homologues of the histone chaperone ASF1 are crucial for chromatin replication and cell 805 proliferation in plant development. The Plant Journal, 66: 443-455.

806

807 Zorrilla-Fontanesi, Y.; Rouard, M.; Cenci, A.; Kissel, E.; Do, H.; Dubois, E.; Nidelet, S.; Roux, 808 N.; Swennen, R.; Carpentier, SC. 2016. Differential root transcriptomics in a polyploidy non809 model crop: the importance of respiration during osmotic stress. Nature Scientific Reports, 6 : $810 \quad 22583$, doi:10.1038/srep22583 
811

PeerJ reviewing PDF | (2017:05:18252:1:2:NEW 26 Jul 2018) 


\section{Figure 1}

Evolution of floral morphology in the Zingiberales.

(a) Most recent Zingiberales phylogeny (modified from Sass et al. (2016)). Zingiberales families are divided into the banana group, a paraphyletic assembly of early branching lineages, and the ginger clade. The asterix $(*)$ marks the evolution of increased petaloidy and reduced number of fertile stamens as shared characteristics of the ginger clade. (b) Musa basjoo flower and floral organs. Calix and corolla members are mostly fused into what is called the floral tube, with the exception of a single corolla member, the free petal. As a representative of the androecial constitution of the banana group, Musa basjoo has 5 filamentous fertile stamens. Musa basjoo gynoecium is also representative of most species in the banana group. (c) Canna sp. flower and floral organs. Species in the ginger clade usually exhibit inconspicuous and sepal-like calix and corolla, while infertile androecial members (staminodes) become laminar and petaloid. Species in the Zingiberaceae and Costaceae families bear a single fertile stamen, while species in the Cannaceae and Marantaceae families only develop $1 / 2$ a fertile stamen. Furthermore, in Canna sp. the gynoecium is also laminarized to some extent. ft: floral tube; fp: free petal; se: sepals; pe: petals; st: stamen; th: theca; std: staminodes; gy: gynoecium (Photo: Ana Almeida) 
(a)

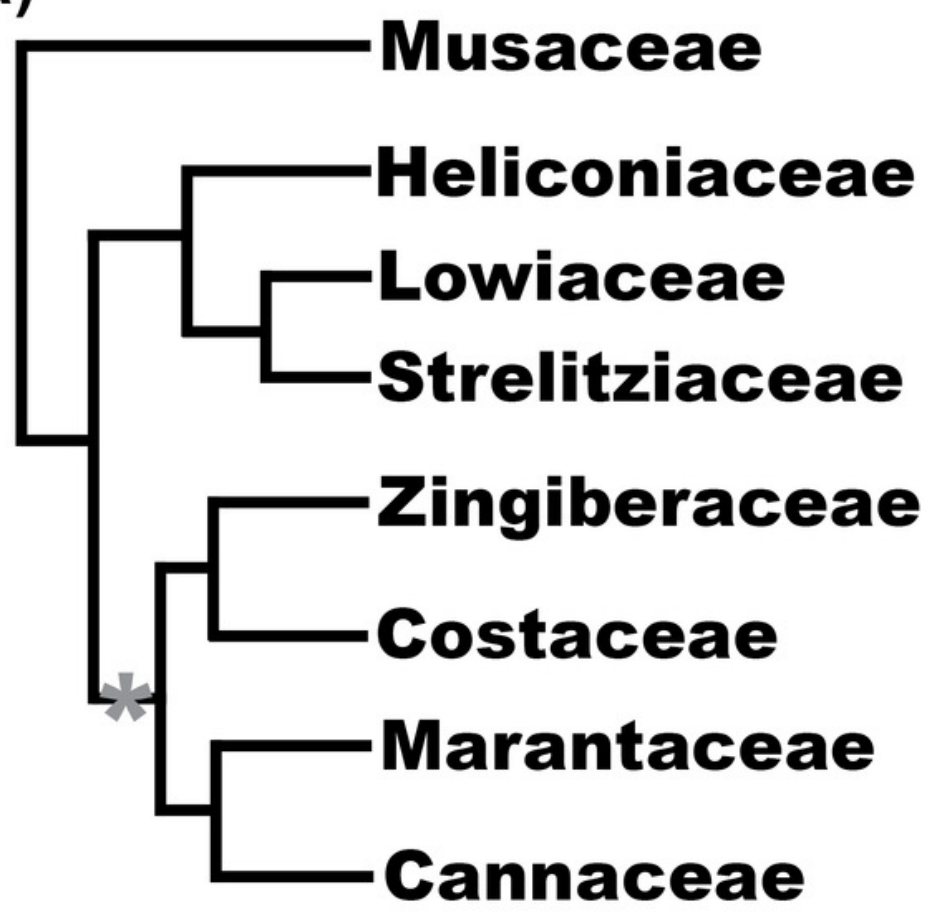

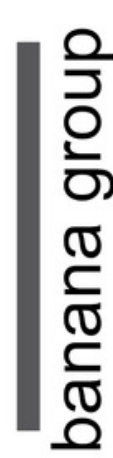

(b)

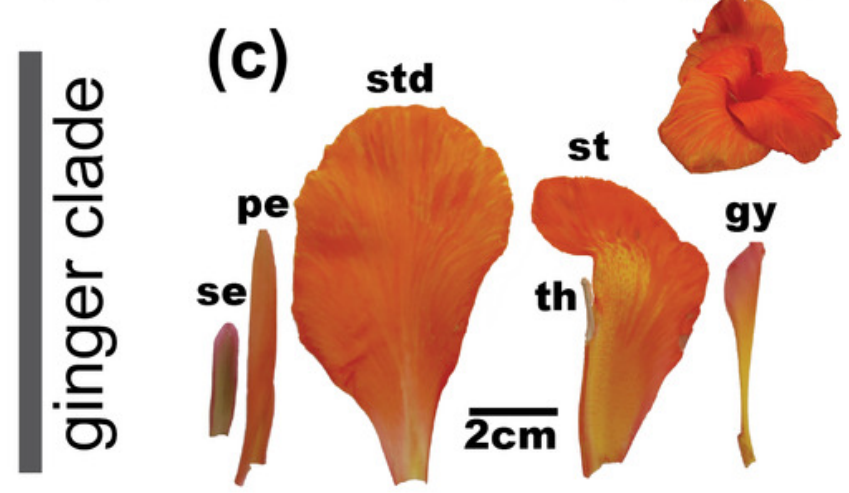


Figure 2

Venn diagram of Blastn results of all floral transcriptomes filtered ORFs against Elaeis guineesis predicted CDS.

Values represent number of unigenes.

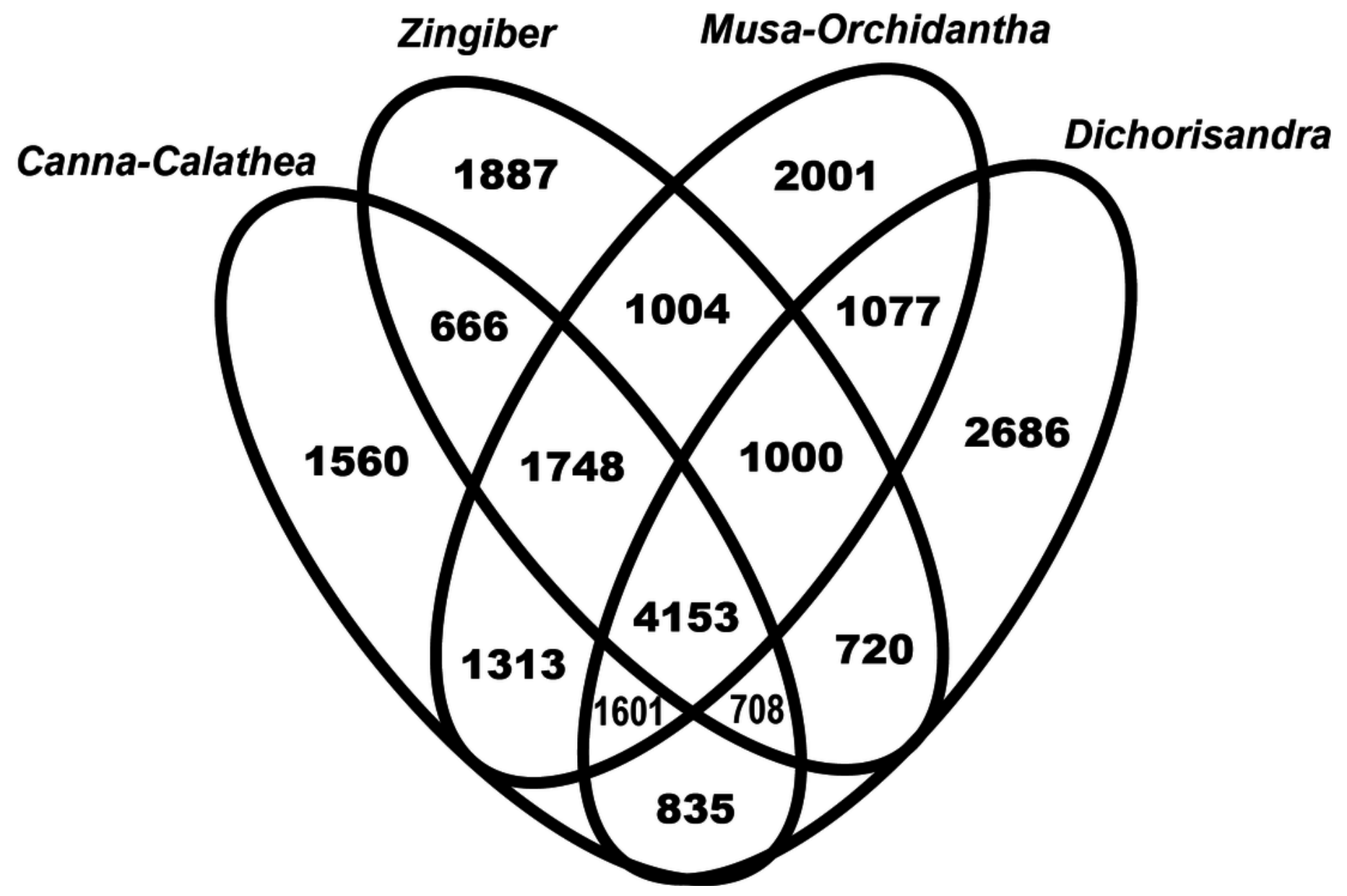


Figure 3

Distribution of main 'functional' categories of coding genes shared by all floral transcriptomes, and shared by all Zingiberales floral transcriptomes based on Blastn results to Elaeis guineesis transcriptome.

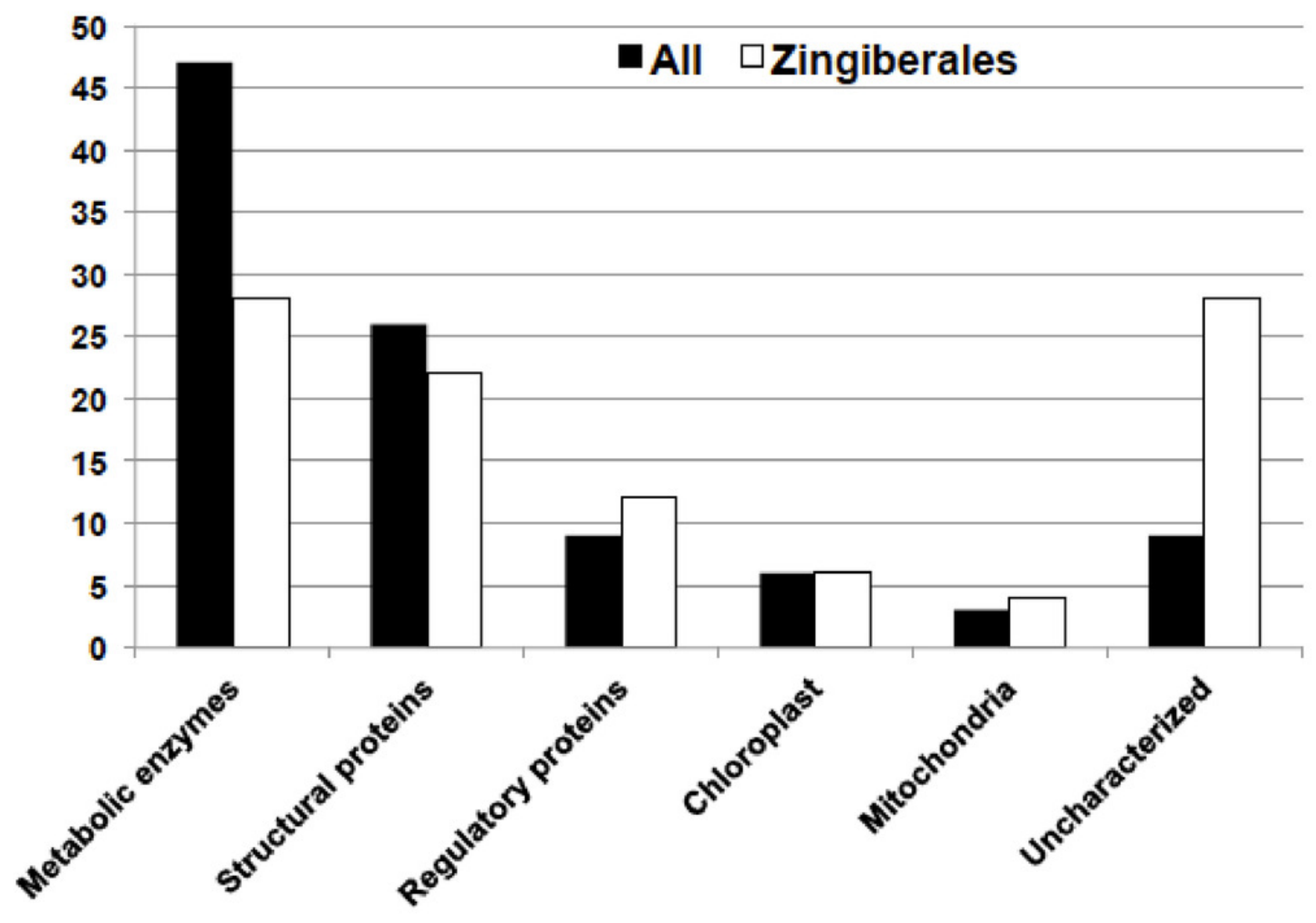




\section{Table 1 (on next page)}

Species used in this study, collection location and accession numbers. 
1

\begin{tabular}{l|l|l}
\hline \multicolumn{1}{c|}{ Species } & \multicolumn{1}{c}{ Location } & Accession \\
\hline Dichorisandra thyrsiflora & UC Davis Greenhouse & B81.521 \\
\hline Musa basjoo & UC Botanical Garden & 89.0873 \\
\hline Orchidantha fimbriata & Oxford Track Greenhouse (UC Berkeley) & 194.656 \\
\hline Canna sp. & Oxford Track Greenhouse (UC Berkeley) & KT795161 \\
\hline Calathea zebrina & UC Botanical Garden & 90.1656 \\
\hline Zingiber officinale & Oxford Track Greenhouse (UC Berkeley) & KT795282 \\
\hline Costus spicatus & Oxford Track Greenhouse (UC Berkeley) & KT795282 \\
\hline
\end{tabular}

2

3

4 


\section{Table 2 (on next page)}

Number of cleaned reads and contigs, average contig length in base pairs, and assembly quality metrics (N50 and RSEM-EVAL scores).

RSEM-scores for each transcriptome were calculated using Arabidopsis, Musa acuminata, Elaeis guineesis and Phoenix dactylifera predicted CDS as references. 
1

\begin{tabular}{l|c|c|c|c|c|c|c|c}
\hline $\begin{array}{l}\text { Whole flower } \\
\text { transcriptomes }\end{array}$ & $\begin{array}{c}\text { Number of } \\
\text { cleaned reads }\end{array}$ & $\begin{array}{c}\text { Number } \\
\text { of contigs }\end{array}$ & $\begin{array}{c}\text { Average } \\
\text { contig length }\end{array}$ & N50 & $\begin{array}{c}\text { RSEM-EVAL to } \\
\text { Arabidopsis CDS }\end{array}$ & $\begin{array}{c}\text { RSEM-EVAL } \\
\text { to Musa CDS }\end{array}$ & $\begin{array}{c}\text { RSEM-EVAL } \\
\text { to Elaeis CDS }\end{array}$ & $\begin{array}{c}\text { RSEM-EVAL to } \\
\text { Phoenix CDS }\end{array}$ \\
\hline $\begin{array}{l}\text { Musa bajsoo } \\
\begin{array}{l}\text { Orchidantha } \\
\text { fimbriata }\end{array}\end{array}$ & $6,103,473$ & 59,607 & 1,177 & 1,635 & -554.921 .347 & -554.925 .496 & -554.909 .485 & -554.930 .293 \\
\hline $\begin{array}{l}\text { Calathea } \\
\text { zebrina }\end{array}$ & $142,860,349$ & 132,411 & 1,724 & 2,440 & -994.730 .221 & -994.728 .623 & -994.727 .315 & -994.729 .011 \\
\hline Canna sp. & $9,357,365$ & 74,190 & 1,113 & 1,503 & -860.726 .519 & -860.732 .496 & -860.711 .867 & -860.736 .385 \\
\hline $\begin{array}{l}\text { Zingiber } \\
\text { officinale }\end{array}$ & $4,643,266$ & 52,798 & 825 & 1,602 & -357.355 .187 & -357.358 .211 & -357.346 .889 & -357.360 .742 \\
\hline $\begin{array}{l}\text { Costus } \\
\text { spicatus }\end{array}$ & $1,292,595$ & 19,377 & 632 & 674 & -95.168 .818 & -95.169 .800 & -95.166 .156 & -95.170 .392 \\
\hline $\begin{array}{l}\text { Dichorisandra } \\
\text { thyrsiflora }\end{array}$ & $6,252,788$ & 64,723 & 891 & 1,166 & -603.219 .814 & -603.224 .077 & -603.211 .474 & -603.225 .657 \\
\hline
\end{tabular}

2 


\section{Table 3(on next page)}

Number of predicted long open reading frames (ORFs) from TransDecoder.

Long ORFs were first predicted from the universe of de novo assembled contigs. Blastp and HMMER3 searchers were used to further filter long ORFs. 
1

\begin{tabular}{|l|c|c|c|c|}
\hline \multirow{2}{*}{$\begin{array}{c}\text { Whole flower } \\
\text { transcriptomes }\end{array}$} & \multicolumn{4}{c|}{ TransDecoder ORF predictions } \\
\cline { 2 - 5 } Musa basjoo & Long ORFs & \% contigs & Filtered ORFs & \% contigs \\
\hline Orchidantha fimbriata & 48,051 & 81 & 29,182 & 49 \\
\hline Calathea zerbina & 39,003 & 58 & 26,790 & 40 \\
\hline Canna sp. & 85,437 & 65 & 55,360 & 42 \\
\hline Zingiber officinale & 43,932 & 59 & 29,366 & 40 \\
\hline Costus spicatus & 39,214 & 74 & 24,463 & 46 \\
\hline Dichorisandra thyrsiflora & 17,112 & 88 & 13,122 & 68 \\
\hline
\end{tabular}

2

3

4

5 


\section{Table 4(on next page)}

Orthogroup species overlap as predicted by OrthoFinder.

Largest number of orthogroup overlap per species is highlighted in bold. Calathea zebrina transcriptome shows the largest number of overlaps to all species, with the exception of Arabidopsis thaliana, potentially resulting from increased transcriptome coverage in that species. 
1

\begin{tabular}{|c|c|c|c|c|c|c|c|c|c|c|}
\hline SPECIES & $\begin{array}{c}A . \\
\text { thaliana }\end{array}$ & $\begin{array}{c}C . \\
\text { zebrina }\end{array}$ & $\begin{array}{c}\text { Canna } \\
\text { sp. }\end{array}$ & $\begin{array}{c}D . \\
\text { thyrsiflora }\end{array}$ & $\begin{array}{c}E . \\
\text { guineensis }\end{array}$ & $\begin{array}{c}M . \\
\text { basjoo }\end{array}$ & $\begin{array}{c}M . \\
\text { acuminata }\end{array}$ & $\begin{array}{c}0 . \\
\text { fimbriata }\end{array}$ & $\begin{array}{c}P . \\
\text { dactylifera }\end{array}$ & $\begin{array}{c}Z . \\
\text { officinale }\end{array}$ \\
\hline $\begin{array}{c}\text { A. } \\
\text { thaliana }\end{array}$ & 11,511 & 10,403 & 10,298 & 10,049 & 10,814 & 10,089 & 10,543 & 9,161 & 9,627 & 9,448 \\
\hline C. zebrina & 10,403 & 29,032 & 20,338 & 15,927 & 11,405 & 19,778 & 12,072 & 16,904 & 11,212 & 16,879 \\
\hline Canna sp. & 10,298 & 20,338 & 25,460 & 14,822 & 11,225 & 18,149 & 11,726 & 15,503 & 10,830 & 15,524 \\
\hline $\begin{array}{c}D . \\
\text { thyrsiflora }\end{array}$ & 10,049 & 15,927 & 14,822 & 20,139 & 10,875 & 14,985 & 11,073 & 13,757 & 10,494 & 13,985 \\
\hline $\begin{array}{c}E . \\
\text { guineensis }\end{array}$ & 10,814 & 11,405 & 11,225 & 10,875 & 13,065 & 10,992 & 11,428 & 9,820 & 11,109 & 10,101 \\
\hline M. basjoo & 10,089 & 19,778 & 18,149 & 14,985 & 10,992 & 26,331 & 12,034 & 15,989 & 10,591 & 15,923 \\
\hline $\begin{array}{c}\text { M. } \\
\text { acuminat } \\
a\end{array}$ & 10,543 & 12,072 & 11,726 & 11,073 & 11,428 & 12,034 & 13,910 & 10,392 & 10,539 & 10,547 \\
\hline $\begin{array}{c}0 . \\
\text { fimbriata }\end{array}$ & 9,161 & 16,904 & 15,503 & 13,757 & 9,820 & 15,989 & 10,392 & 22,244 & 9,644 & 14,164 \\
\hline $\begin{array}{c}P . \\
\text { dactylifer } \\
a\end{array}$ & 9,627 & 11,212 & 10,830 & 10,494 & 11,109 & 10,591 & 10,539 & 9,644 & 13,156 & 9,805 \\
\hline $\begin{array}{c}Z . \\
\text { officinale }\end{array}$ & 9,448 & 16,879 & 15,524 & 13,985 & 10,101 & 15,923 & 10,547 & 14,164 & 9,805 & 21,568 \\
\hline
\end{tabular}

2 


\section{Table 5 (on next page)}

Blastn results between floral transcriptomes and predicted coding sequences (CDS) from the genomes of Arabidopsis thaliana, Musa acuminata, Phoenix dactylifera, and Elaeis guineensis. 


\begin{tabular}{|c|c|c|c|c|c|c|}
\hline \multirow[b]{2}{*}{ Transcriptomes } & \multicolumn{3}{|c|}{ Musa acuminata } & \multicolumn{3}{|c|}{ Elaeis guineensis } \\
\hline & $\begin{array}{c}\text { Blastn } \\
\text { all } \\
\text { contigs } \\
\text { to CDS }\end{array}$ & $\begin{array}{l}\text { CDS represented } \\
\text { in transcriptome }\end{array}$ & $\begin{array}{c}\% \text { CDS } \\
\text { represented in } \\
\text { transcriptome }\end{array}$ & $\begin{array}{c}\text { Blastn } \\
\text { all } \\
\text { contigs } \\
\text { to CDS }\end{array}$ & $\begin{array}{l}\text { CDS represented } \\
\text { in transcriptome }\end{array}$ & $\begin{array}{c}\% \text { CDS } \\
\text { represented in } \\
\text { transcriptome }\end{array}$ \\
\hline Musa bajsoo & 49,127 & 29,433 & 80.5 & 19,509 & 19,945 & 44.96 \\
\hline $\begin{array}{l}\text { Orchidantha } \\
\text { fimbriata }\end{array}$ & 38,170 & 20,289 & 55.5 & 21,317 & 18,238 & 41.11 \\
\hline Calathea zebrina & 75,885 & 20,671 & 56.5 & 42,638 & 17,229 & 38.84 \\
\hline Canna sp. & 35,597 & 20,522 & 56.1 & 19,353 & 17,723 & 39.95 \\
\hline Zingiber officinale & 16,901 & 14,322 & 39.2 & 8,725 & 11,886 & 26.79 \\
\hline Costus spicatus & 9,319 & 9,223 & 25.2 & 4,491 & 6,430 & 14.5 \\
\hline $\begin{array}{l}\text { Dichorisandra } \\
\text { thyrsiflora }\end{array}$ & 12,384 & 8,596 & 23.5 & 11,394 & 12,780 & 28.81 \\
\hline \multirow[b]{2}{*}{ Transcriptomes } & \multicolumn{3}{|c|}{ Phoenix dactylifera } & \multicolumn{3}{|c|}{ Arabidopsis thaliana } \\
\hline & $\begin{array}{c}\text { Blastn } \\
\text { all } \\
\text { contigs } \\
\text { to CDS }\end{array}$ & $\begin{array}{l}\text { CDS represented } \\
\text { in transcriptome }\end{array}$ & $\begin{array}{c}\% \text { CDS } \\
\text { represented in } \\
\text { transcriptome }\end{array}$ & $\begin{array}{c}\text { Blastn } \\
\text { all } \\
\text { contigs } \\
\text { to CDS }\end{array}$ & $\begin{array}{l}\text { CDS represented } \\
\text { in transcriptome }\end{array}$ & $\begin{array}{c}\% \text { CDS } \\
\text { represented in } \\
\text { transcriptome }\end{array}$ \\
\hline Musa bajsoo & 15,586 & 9.015 & 31.21 & 2,136 & 1,571 & 4.44 \\
\hline $\begin{array}{l}\text { Orchidantha } \\
\text { fimbriata }\end{array}$ & 17,473 & 8,185 & 28.33 & 2,268 & 1,410 & 3.98 \\
\hline Calathea zebrina & 35,226 & 7,685 & 26.6 & 5,108 & 1,591 & 4.5 \\
\hline Canna sp. & 14,940 & 7,702 & 26.66 & 2,055 & 1,624 & 4.59 \\
\hline Zingiber officinale & 6,544 & 5,077 & 17.57 & 1,436 & 1,295 & 3.66 \\
\hline Costus spicatus & 3,354 & 2,816 & 9.75 & 706 & 743 & 2.10 \\
\hline $\begin{array}{l}\text { Dichorisandra } \\
\text { thyrsiflora }\end{array}$ & 8,856 & 5,403 & 18.7 & 1,827 & 1,507 & 4.26 \\
\hline
\end{tabular}




\section{Table 6(on next page)}

Distribution of transcription factor families amongst the floral transcriptomes studied.

A total of 508 transcription factors were ascribed to 36 of the 58 plant transcription factor families characterized in the PlantTFDB v4.0. Outgroup species is Dichorisandra thyrsiflora. 
1

\begin{tabular}{|l|c|c|c|c|c|c|c|}
\hline & $\begin{array}{c}\text { Shared } \\
\text { by all }\end{array}$ & Zingiberales & $\begin{array}{c}\text { Banana } \\
\text { clade }\end{array}$ & $\begin{array}{c}\text { Ginger } \\
\text { clade }\end{array}$ & $\begin{array}{c}\text { Canna- } \\
\text { Calathea }\end{array}$ & $\begin{array}{c}\text { Zingiber } \\
\text { (Dichorisandra } \\
\text { thyrsiflora) }\end{array}$ \\
\hline $\begin{array}{l}\text { Transcription } \\
\text { Factor } \\
\begin{array}{l}\text { Families } \\
\text { (PlantTFDB } \\
\text { v4.0) }\end{array}\end{array}$ & 25 & 22 & 19 & 18 & 20 & 30 & 21 \\
\hline $\begin{array}{l}\text { Putative } \\
\text { Transcription } \\
\text { Factors (not } \\
\text { in PlantTFDB } \\
\text { v4.0) }\end{array}$ & 0 & 0 & 1 & 0 & 2 & 3 & 2 \\
\hline
\end{tabular}

2

3 